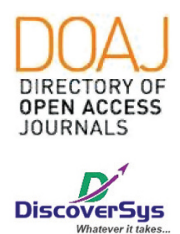

Published by DiscoverSys

\section{The suitability of sputum and blood culture in children with pneumonia at Sanglah General Hospital, Bali, Indonesia}

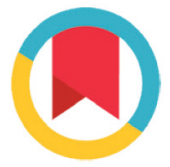

CrossMark

\author{
Ayu Setyorini Mestika Mayangsari ${ }^{1 *}$, Ida Bagus Subanada ${ }^{2}$, Putu Siadi Purniti ${ }^{2}$, \\ Wayan Agustini Selumbung ${ }^{2}$
}

\title{
ABSTRACT
}

Background: Pneumonia is one of the diseases in children with high morbidity, especially in children under 5 years old. In developing countries, the most common cause of pneumonia is bacteria. There is a newer method that gives a better reflection of the aetiology, which is the sputum examination. This study aims to determine the suitability of sputum and blood culture in children with pneumonia at Sanglah General Hospital, Bali.

Methods: A cross-sectional study was conducted at Respirology Subdivision in Department of Child Health Sanglah Hospital from November 2016 until February 2017. A categorical comparative matching was carried out between 2 formula groups. The sputum culture and blood culture were obtained through Microbiology Laboratory at Sanglah General Hospital. Data were analysed using
SPSS version 16 for Windows.

Results: There were 50 children with pneumonia enrolled in this study. The children aged less than 1 years old were predominant (62\%). There were a statistically systematic difference and only a fair agreement between blood and sputum culture $(\mathrm{k}=0.257$; $\mathrm{p}=0.004$ ). In a subject with positive sputum culture, $90.9 \%$ had a better outcome than the positive blood culture even though no statistically significant ( $R R=0.23 ; 95 \% \mathrm{Cl}: 0.15-22.53$ )

Conclusion: There is suitability between the culture of sputum and blood cultures in children with pneumonia. Sputum culture has a higher probability to reveal the microorganism compared to blood cultures.
'Department of Child Health, Medical School, Universitas Udayana, Universitas Udayana Hospital, Bali, Indonesia ${ }^{2}$ Department of Child Health, Medical School, Universitas Udayana, Sanglah General Hospital, Bali, Indonesia

*Corresponding to: Ayu Setyorini Mestika Mayangsari; Department of Child Health, Medical School, Universitas Udayana, Universitas Udayana Hospital, Bali, Indonesia; setyorinimestika@yahoo.com

Received: 2019-09-05 Accepted: 2019-09-21 Published: 2019-12-01

Keywords: pneumonia, sputum culture, blood culture

Cite This Article: Mayangsari, A.S.M., Subanada, I.B., Purniti, P.S., Selumbung, W.A. 2019. The suitability of sputum and blood culture in children with pneumonia at Sanglah General Hospital, Bali, Indonesia. Intisari Sains Medis 10 (3): 616-619. D0I: 10.15562/ism.v10i3.606

\section{INTRODUCTION}

Pneumonia is one of the diseases in children with high morbidity, especially in children under 5 years old. The mortality of pneumonia in developed countries such as the USA in 1 year ranged from 40,000 to 70,000 people. ${ }^{1,2}$ In Indonesia, based on Indonesias health profile data in 2015, the prevalence of pneumonia in infants is $0.76 \%$ where the highest prevalence was in Gorontalo (13.2\%) and Bali (12.9\%). Prevalence of pneumonia in infants in Bali was 30\%, whereas in children aged 1-4 years the prevalence was $69 \%{ }^{3}$

In developing countries, the most common cause of pneumonia is bacteria, whereas the virus is the most frequent cause in developed countries. A common method to determine the cause is blood cultures. Unfortunately, this method has some limitations in determining the aetiology of pneumonia. First, although it reflects infection in the blood, blood cultures do not specifically show the cause of infection in the lung. It only gives positive results in $10-15 \%$ of pneumonia cases. ${ }^{4}$ Second; this method is quite invasive because it is done by taking the blood from two sides and therefore more expensive. Third, the complete result of blood culture takes up to one week and sometimes longer. New methods that give better reflection, faster, and cheaper of the aetiology of lower respiratory tract infection are needed. One of the methods is sputum examination. Previously, Miyashita et al. and Garcia et al. studies showed that sputum culture shows a more prominent value in finding the microorganism that causes pneumonia, which is $88 \%$ and $54 \%$ respectively. ${ }^{5,6}$ Sputum retrieval is done by sputum induction and suctioning the mucus with sterile mucus extractor. Finding the specific microorganism that causes pneumonia is essential as it plays a significant role for clinicians to give appropriate therapy and prognosis.

Until now, there has been limited data of sputum cultures in Indonesia and most studies about 
pneumonia based on blood cultures. Our primary aim is to look at the congruency of sputum and blood cultures in children with pneumonia, and the secondary objective is to see whether there is a relationship between sputum and blood culture with outcome of pneumonia in children.

\section{METHODS}

A cross-sectional study was conducted at Respirology Subdivision in Child Health Department of Sanglah Hospital/Universitas Udayana. This study was conducted by taking samples of patients who were admitted with pneumonia in Sanglah hospital from November 2016 until February 2017. The children who were diagnosed with pneumonia or severe pneumonia and didn't get any antibiotics previously were included. Parents refusal to participate was an exclusion criterion in this study. The sputum culture and blood culture were obtained through the Microbiology Laboratory at Sanglah hospital. The population target in this study were all children with pneumonia. The research population was all the children who were treated with pneumonia at Sanglah hospital from November 2016-February 2017. For sample size calculation, we used categorical comparative matching between 2 formulae groups with a standard normal variate at $5 \%$ where type I error is 1.96 , power $80 \%$, and expected effect size $20 \%$ to get a minimum of 46 samples consecutively.

The study variables were age, gender, nutritional status, sputum culture, and blood culture results. Sputum was collected with induced sputum procedure. The patient was pretreated with $0.1 \mathrm{mg} /$ $\mathrm{kg}$ BW salbutamol in $0.9 \% \mathrm{NaCl}$ until $4 \mathrm{~mL}$ solution.

Table 1. Baseline characteristic of respondents

\begin{tabular}{|c|c|}
\hline Clinical feature & N (\%) \\
\hline Sex, male & $25(50)$ \\
\hline \multicolumn{2}{|l|}{ Age } \\
\hline $0-1$ year & $31(62)$ \\
\hline $2-5$ years & $16(32)$ \\
\hline$>5$ years & $3(6)$ \\
\hline \multicolumn{2}{|l|}{ Nutritional status } \\
\hline Mild malnutrition & $12(24)$ \\
\hline Well-nourished & $29(58)$ \\
\hline Overweight & $9(18)$ \\
\hline \multicolumn{2}{|l|}{ Sputum culture } \\
\hline Positive & $11(22)$ \\
\hline Negative & $39(78)$ \\
\hline \multicolumn{2}{|l|}{ Blood culture } \\
\hline Positive & $2(4)$ \\
\hline Negative & $48(96)$ \\
\hline Outcome, death & $3(6)$ \\
\hline
\end{tabular}

Ten minutes later, the patient was nebulised with 4 $\mathrm{mL}$ of $3 \% \mathrm{NaCl}$. After that, the sputum was obtained by spontaneous expectoration or suctioning the nasopharynx with sterile mucus extractor. The minimal amount of sputum collecting was $4 \mathrm{~mL}$. Blood is taken on both side of the patient's arm, then inserted into sterile media and cultured using media agar. Sputum and blood sample was sent to Sanglah Hospital/Universitas Udayana, Microbiology Department. These both cultures placed in media agar and using VITEX 2 for identification and antibiotic susceptibility testing.

Diagnosis of pneumonia was made by clinical definition of WHO that was respiratory disease characterised by a cough, fast breathing, fever, and infiltrates on the chest $\mathrm{x}$-ray. Nutritional status was classified using Waterlow criteria into severe malnutrition $(<70 \%)$, mild malnutrition $(70-89 \%)$, well-nourished (90-110\%), overweight (110$120 \%)$, and obesity (>120\%). The sputum culture is the result of microorganism growth after the sputum sample was processed with special media. It is classified into positive if there is growth and negative if no growth of such microorganism. Blood culture is the result of microorganism growth after the blood sample was processed with special media. It is classified into positive if there is growth and negative if no growth of such microorganism. The outcome is the last condition of the subject in the hospital that divided into life and death.

The data obtained are presented in the form of narration and table. In descriptive statistics, we showed the characteristics of the sample according to study variables. To see the suitability between sputum and blood culture, we used Mc Nemar test continued with the degree of agreement by Cohen's Kappa calculation. To compare sputum and blood culture with the outcome, we used Chi-Square test. Research data were analysed using SPSS version 16.0 with a p-value of $<0.05$ was considered to be significant. This study was approved by Research Ethics Commission Faculty of Medicine Udayana University/Sanglah Hospital with letter number 1868/UN.14.2/Litbang/2016.

\section{RESULTS}

Fifty respondents meet the inclusion criteria included in this study. Characteristics of the subjects are shown in Table 1. Mostly ranged between 0-1 years old (62\%) and 58\% were with good nutrition status. In Addition, the recent study also found that most of sputum or blood culture was negative (78\% and $96 \%$, respectively). There were only $3(6 \%)$ cases death during study period (Table 1).

There is a systematic difference between sputum and blood culture with p-value 0.004. In a further 
Table 2. The analysis of agreement between sputum and blood culture

\begin{tabular}{ccccc}
\hline \multirow{2}{*}{$\begin{array}{c}\text { Sputum } \\
\text { Culture }\end{array}$} & $\begin{array}{c}\text { Positive } \\
\mathbf{( N , \% )}\end{array}$ & $\begin{array}{c}\text { Negative } \\
\mathbf{( N , \% )}\end{array}$ & $\begin{array}{c}\text { Agreement } \\
\mathbf{N}(\%)\end{array}$ & $\mathbf{P}$ \\
\cline { 2 - 3 } Positive & $2(4)$ & $9(18)$ & $41(82)$ & $0.004^{*}$ \\
Negative & $0(0)$ & $39(78 \%)$ & & \\
\hline
\end{tabular}

${ }^{*}$ McNemar test: statistically significant if less than 0.05

Table 3. Analysis of culture with the outcome

\begin{tabular}{lcccccc}
\hline \multirow{2}{*}{ Variable } & \multicolumn{2}{c}{ Death } & & & \\
\cline { 2 - 3 } & Positive & Negative & & RR & P & $\mathbf{9 5 \%} \mathbf{~ C l}$ \\
\hline Blood culture & $\mathbf{N}(\%)$ & $\mathbf{N ~ ( \% )}$ & & & \\
Positive & $1(50.0 \%)$ & $1(50.0 \%)$ & 1.3 & 0.12 & $1.02-51.69$ \\
Negative & $2(4.2 \%)$ & $46(95.8 \%)$ & & & \\
\hline Sputum culture & & & & & \\
Positive & $1(9.1 \%)$ & $10(90.9 \%)$ & 0.23 & 0.53 & $0.15-22.53$ \\
Negative & $2(5.1 \%)$ & $37(94.9 \%)$ & & & \\
\hline
\end{tabular}

RR: relative risk; CI: confidence interval

Table 4. Bacteria in sputum and blood culture

\begin{tabular}{ll} 
Sputum culture & Streptococcus pneumonia (4) \\
& Klebsiella pneumonia (1) \\
& Staphylococcus coagulase negative (6) \\
\hline Blood culture & Staphylococcus aureus (2) \\
\hline
\end{tabular}

analysis with Cohen's Kappa, the agreement $(\mathrm{k})$ is 0.257 with $95 \%$ CI $0.15-0.71$, which showed the agreement between both cultures only fair (Table 2). We found there is no relation between positive result in sputum and blood culture with the outcome. Although there's no significant relationship between sputum culture result and death outcome, we proceed to calculate the validity of sputum culture to discriminate between death and life outcome. We found that sputum culture has sensitivity $90 \%$, specificity $5 \%$, positive predictive value $21 \%$, and negative predictive value $67 \%$ in determining death outcome. For blood culture, we got sensitivity $50 \%$, specificity $4 \%$, positive predictive value $2 \%$, negative predictive value $67 \%$ (Table 3). The analysis of culture with outcome also exhibit no statistically significant with the relative risk (RR) (Table 3).

Three kinds of bacteria revealed a positive result in sputum culture, and only one bacterium was positive in blood culture. Several types of bacteria found in sputum culture was Streptococcus pneumonia, Klebsiella pneumonia, and Staphylococcus coagulase. However, Staphylococcus aureus only found in blood culture (Table 4).

\section{DISCUSSION}

Blood culture still plays a role in pneumonia treatment in children. Despite the low rate of a positive result, it is still routinely done at some medical centres in the management of pneumonia. The main reason is due to the lack of ability to obtain a sample from deeper tissues like bronchoalveolar sputum or lung tissue biopsy. It is hoped that by blood culture the clinician could capture a glimpse of microorganism that causes the infection and adjust the antibiotic according to the microorganism sensitivity. There is still a growing need to find another tool to detect the microorganism that reflects the actual condition of the lower respiratory tract in a better way. In this study, we proved that the possibility to get a positive result for culture is higher from sputum compare to blood specimen in children with pneumonia. Furthermore, there is a systematic difference and only fair agreement between blood and sputum culture. This difference could be a source of bias in the management of pneumonia and could lead to higher morbidity and mortality. This study is in line with the study of Seksan et $\mathrm{al}^{7}$ and Lahti et al., which found insignificant suitability between sputum and blood culture (p 0.447). ${ }^{8}$

Sputum culture is a better way compared to blood culture for identification of microorganisms that causes pneumonia in facilities that have no bronchoscopy in children. We try to compare the sputum and blood culture result in death outcome of the subject. It appears that with positive blood culture results, more patient died compare with positive sputum culture. The plausible biology reason for this is as follows. The positive blood cultures indicating that there is sufficient number of microorganisms in the bloodstream so it is reasonable to find more systemic involvement and severity that could affect the outcome.

On the other hand, in a subject with positive sputum cultures but negative blood culture, the microorganism must be localised only in the respiratory tract area with less systemic involvement and therefore less severe. In accordance with this study, Shah et al. and Angela et al. showed that patients with positive blood cultures had clinically more severe pneumonia (62.5\%) and mortality rate $(51.2 \%) .{ }^{9,10}$ Unfortunately, we didn't find a significant association between both culture result and the outcome. 
Since we found a higher positive predictive value of sputum culture, it can be concluded that sputum culture has a higher probability to reveal the microorganism compared with blood cultures. In the future, we suggest doing sputum culture for every patient with pneumonia because an additional 18\% benefit to capture the microorganism will be missed if blood culture is the only tool used. If sputum culture results showed growth of microorganism, we could base the treatment on that and sparse the blood culture examination only for more clinical systemic manifestation or if the patient failed to respond. In this study, we can convince that the specimen we obtained was from respiratory tract because the epithelial cell is less than +2 .

The limitations of this study are as follows. First, there is no rigorous gold standard because we could not do bronchoalveolar lavage or thoracocentesis. Second, the negative blood culture results can be caused by lack of specimen volume, poor storage and delivery methods to the microbiology lab. Third, we didn't specify the pneumonia severity and did not record the comorbid disease that could affect the possibility to find positive culture result and the deadly outcome. Fourth, we could not examine for viral infection due to lack of proper tool in our facility. As we know dual infection between viral and bacterial is frequent and could affect the morbidity and mortality of the patient.

\section{CONCLUSION}

In conclusion, there is a systematic difference and only fair agreement between sputum and blood culture, and no relationship between sputum and blood culture with mortality in children with pneumonia.

\section{ETHICS CONSIDERATION}

This study was approved by Research Ethics Commission Faculty of Medicine Udayana University/Sanglah Hospital with letter number 1868/UN.14.2/Litbang/2016.

\section{CONFLICT OF INTEREST}

There is no competing interest regarding the manuscript

\section{FUNDING}

The authors are responsible for the funding of study without the involvement of grant, scholarship, sponsorship, or any other resources of funding

\section{AUTHORS CONTRIBUTION}

All of the authors are equally contributed to the study from the conceptual framework, data gathering, data analysis, until reporting the results of study.

\section{REFERENCES}

1. Fekadu GA, Terefe MW, Alemia GA. Prevalence of Pneumonia Among Under- Five Children in Este Town and the Surrounding Rural Kebeles, Northwest Ethiopia; A Community Based Cross-Sectional Study. Science Journal of Public Health. 2014;2(3):150-5.

2. Gray D, Zar HJ. Childhood Pneumonia in Low and Middle Income Countries: Burden,Prevention and Management. Infectious Diseases Journal. 2010;4:74-84.

3. Kementerian Kesehatan Republik Indonesia. Profil Kesehatan Indonesia. 2015

4. Mendel LA, Wuderink RG, Anzueto A, Bartlett JG, Campbell GD, Dean NC, et al. Infectious Disease Society of America/American Thoracic Society consensus guidelines on the management of community- acquired pneumonia in adults. Clinical Infectious Disease. 2007;44 Suppl 2:S2772 .

5. Miyashita N, Shimizu H, Ouchi K, Kawasaki K. Assessment of the usefulness of Sputum Gram Stain and culture for diagnosis of community-acquired pneumonia requiring hospitalization. Med Sci Monit. 2008;14(4):171-6.

6. Garcia E, Vasquez,MA, Marcos J, Mensa A. Assessment of the usefulness of sputum culture for diagnosis of community-acquired pneumonia using PORT predictive scoring system. Arch Intern Med. 2004;164(16):1807-11.

7. Seksan C, Apisak K, Kittisak S, et al. Appropriateness of obtaining blood cultures in patients with community acquired pneumonia. Southeast Asian J TropMed PublicHealth. 2013;44(2):289-94.

8. Lahti E, Peltola V, Waris M, Virkki R, Rantakokko-Jalava K, Jalava J, et al. Induced sputum in the diagnosis of childhood community-acquired pneumonia. Thorax. 2009;64(3):2527.

9. Shah SS, Dugan MH, Bell LM et al. Blood cultures in the emergency department evaluation of childhood pneumonia. Pediatr Infect Dis J. 2011;30(6):475-9.

10. Angela LM, Matthew H, Derek JW, et al. Prevalence of bacteremia in hospitalized pediatric patients with community-acquired pneumonia. Pediatr Infect Dis J. 2013;32(7):736-40.

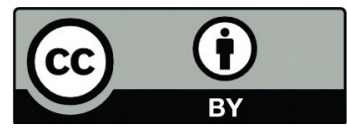

This work is licensed under a Creative Commons Attribution 